\title{
Implementing Rule-based Healthcare Edits
}

\author{
Umair Abdullah $^{1 *}$, Muhammad Shaheen², and Farhan Sabir Ujager ${ }^{3}$ \\ ${ }^{1}$ MaxRemind Research and Development, \\ MaxRemind Inc. Rawalpindi, Pakistan \\ [e-mail: umairabdullah@mremind.com, umair_pitafi@yahoo.com] \\ ${ }^{2}$ Faculty of Engineering \& IT \\ Foundation University, \\ Islamabad, Pakistan \\ [e-mail: dr.shaheen@fui.edu.pk] \\ ${ }^{3}$ Faculty of Computing, Engineering and Media, \\ De Montfort University, \\ Dubai, UAE \\ [e-mail: farhan.ujager@dmu.ac.uk] \\ *Corresponding author: Umair Abdullah
}

Received August 29, 2021; revised October 17, 2021; accepted November 12, 2021; published January 31, 2022

\begin{abstract}
Automated medical claims processing and billing is a popular application domain of information technology. Managing medical related data is a tedious job for healthcare professionals, which distracts them from their main job of healthcare. The technology used in data management has a sound impact on the quality of healthcare data. Most of Information Technology (IT) organizations use conventional software development technology for the implementation of healthcare systems. The objective of this experimental study is to devise a mechanism for use of rule-based expert systems in medical related edits and compare it with the conventional software development technology. A sample of 100 medical edits is selected as a dataset to be tested for implementation using both technologies. Besides empirical analysis, paired t-test is also used to validate the statistical significance of the difference between the two techniques. The conventional software development technology took 254.5 working hours, while rule-based technology took 81 hours to process these edits. Rule-based technology outperformed the conventional systems by increasing the confidence value to $95 \%$ and reliability measure to 0.462 (which is $<0.5$ ) which is three times more efficient than conventional software development technology.
\end{abstract}

Keywords: Healthcare Data, Healthcare Applications, Electronic Healthcare Records, Healthcare professionals, Rule based Systems, Rule-based approach.

This research work has been supported by Higher Education Commission of Pakistan under ' 5000 - indigenous Ph.D. Fellowships Scheme'. 


\section{Introduction}

Healthcare overtime has become an important domain in the field of information technology due to the conjunction of technology and its use in different applications. Use of software technology seem becoming a need for management and processing of healthcare data [1, 2] and clinical documents [3]. Quality of healthcare is directly proportional to the quality of data stored in healthcare related software like EHRs, Billing Management Systems, Patient Health Records, Integrated Healthcare Systems [4-6].

Thousands of regular and periodic edits has made it slightly unmanageable for software vendors to cope with the changing requirements of health informatics domain [7]. Just use of software technology is not sufficient for improving quality of data and health informatics, underlying tools and techniques greatly impact the ability of software for proper management and processing of data [8]. This manuscript is for experts working in healthcare informatics domain. The manuscript discusses the underlying technologies of designing and developing healthcare related software. Two of the said technologies are compared in this study for the measurement of efficiency in implementation of medical coding/billing knowledge.

For healthcare IT professionals working in the domains of medical billing and computer programming, implementing medical edits sometimes becomes very complex. Medical edits include Mutually Exclusive Edits (MEE), Medically Unlikely Edits (MUE), Correct Coding Initiative (CCI) edits, Add-on Code Edits etc. The complexity of the task can be reduced by issuing specific instructions, related to coding and billing, given by individual providers. This research paper reports an important finding by comparing two underlying technologies of healthcare IT system development i.e. conventional programming technology and rule-based technology.

A brief overview of health informatics, issues and challenges is presented in the next section. A generic description of two technologies; rule-based expert systems' technology and conventional software development technology, is then presented. In Section 2, Objectives of study have been presented. Section 3 is about the methodology of research. The results obtained during the research along with the statistical analysis are presented in Section 4 which is followed by the synthesis of paper in conclusion section presented at the end.

\subsection{Health Informatics}

This section presents snapshot of the needs and challenges of health informatics domain. Besides, user acceptance/adoptability, security and privacy of data, other major issues are data quality [6] and change flexibility which is the focus of this research study. Many organizations are working on these lines to overcome these issues. The organizations will be able to develop a more comprehensive health care system after addressing these issues and for which a cohesive Healthcare Information System is proposed [9]. For information and data sharing among programs, systems and institutions, all of the healthcare systems comprise of standardized set of procedures. Benefits of these healthcare systems include prompt information availability to providers, assurance of continuous care and inter-disciplinary communication [10].

Although multiple studies hypothesize the process of developing healthcare information systems yet only fewer offer the recommendations about it [11]. In [12], strategy method with a key element of 'flexible standard' is proposed for developing healthcare infrastructure. 
These flexible standards have two dimensions; 'change flexibility' and 'use flexibility'. 'Change flexibility' refers to the changeability through modularization, and 'Use flexibility' refers to the magnitude with which multiple activities and tasks can be executed by a system. Moreover, some other issues related to medical billing processing are: 1 . massive amount of heterogeneous data is to be processed, and 2. semantic aspects of data are to be considered, which implies that the information should be processed in such a way that it becomes readable and understandable by man and computer. This led us to use declarative knowledge representation (i.e. production rules) for implementation of healthcare edits.

Although, hundreds of EHRs, PHRs, and other healthcare information systems have been developed yet these systems cannot go beyond the capabilities of underlying conventional software development tools and techniques. Conventional programming technique cannot provide flexibility of change and use. This causes deterioration in quality of data with an exponential speed with the passage of time. The deterioration in the quality of data can ultimately effect patient safety and care [13].

Two techniques; conventional programming and rule-based programming have been scientifically compared in this research study. The following section presents a generic comparison of these two techniques, which will be followed by the hypothesis of the study.

\subsection{Rule-Based Expert Systems a classical Al Technology}

This section introduces the underlying technology of developing rule-based expert system, which is a classical technique of Artificial Intelligence, although initiated in 1970s in healthcare domain but nowadays frequently available in healthcare domain [14]. Rule-based programming is used to develop rule-based expert systems that can achieve change flexibility, hence can maintain quality of data with the passage of time [19], which ultimately contributes to better patient care.

Systems developed using rule-based programming comprises of three basic components namely knowledge base (a collection of 'rules'), working memory and inference engine [15, 16]. Inference engines are those specified applications that are capable of reading a particular set of rules from the knowledge base, on input conditions pick the suitable rule and execute the conforming actions[14]. Rules are made up of if-then structures having diverse properties with respect to representation and computation. In rule-based programming, the term 'rule' (also known as 'production rule') refers to 'if-then' structure whereas 'if' represents condition and 'then' is followed by the action part.

$$
\text { IF }<\text { condition }>\text { THEN }<\text { action }>
$$

The production rule is written in the form of conventional if-then statement that is used as conditional control statement in the programming languages. The production rule, however, is based on the dataset and is applied onto the attributes of a database, that makes it different from the if-then used in programming languages $[14,17]$. Coding in different programming languages requires specialized programming skills, time taken to execute a program, debugging and other incremental costs.

\subsection{Conventional Software Development Technology}

In conventional software systems, business rules (conditions and actions) are encoded in the form of compiled codes written in some programming language like Java, $\mathrm{C}++$, C\#, etc. With 
new innovations in healthcare new edits (conditions and actions) are required to be implemented on the monthly or quarterly basis, which in turn may induce new bugs in the software; and excessive time is wasted to eradicate those bugs. In conventional software 'if' statements are used (instead of production rules) as part of code and only persons with programming skills can change the code. Therefore, in case of conventional programming based software, professionals of healthcare domain are not able to incorporate updated knowledge in software by themselves. Some aspects of rule-based programming and conventional programming have been summarized in the Table 1.

Table 1. Comparison of Rule-Based programming and conventional programming

\begin{tabular}{|c|c|c|}
\hline Characteristics & Rule Based Technology & $\begin{array}{c}\text { Conventional Software } \\
\text { Technology }\end{array}$ \\
\hline $\begin{array}{c}\text { Type of } \\
\text { Programming }\end{array}$ & Declarative & Procedural \\
\hline Development Tools & $\begin{array}{l}\text { Special Artificial intelligence languages } \\
\text { (LISP, PROLOG) or in specific tools } \\
\text { like OPS-5, KEE, SQL, CLISP, Jess, } \\
\text { Drools, ILOG Rules, G2. etc. }\end{array}$ & $\begin{array}{l}\text { Compiled languages like Java, } \\
\mathrm{C}++, \mathrm{C} \#, \mathrm{VB} \text {, etc. are used to } \\
\text { develop conventional software. }\end{array}$ \\
\hline $\begin{array}{c}\text { Implementation of } \\
\text { Conditions and } \\
\text { Actions } \\
\end{array}$ & Production rules & $\begin{array}{l}\text { Condition control statements } \\
\text { including switch statement }\end{array}$ \\
\hline $\begin{array}{l}\text { Checks incorporated } \\
\text { within the data and } \\
\text { programming code }\end{array}$ & Data & Code \\
\hline $\begin{array}{c}\text { System } \\
\text { Specification } \\
\end{array}$ & Changeability and runtime managed & Complex, static \\
\hline Processing zone & Centralized on database. & \\
\hline $\begin{array}{c}\text { All validation } \\
\text { Checks are applied } \\
\text { on the dataset which } \\
\text { updates the database } \\
\text { directly. }\end{array}$ & $\begin{array}{l}\text { Decentralized (mostly client-server } \\
\text { model). Processing can be done on both } \\
\text { client and server side. }\end{array}$ & \\
\hline Efficiency & $\begin{array}{l}\text { More efficient because of direct } \\
\text { implementation at the database. }\end{array}$ & $\begin{array}{c}\text { Less efficient due to excessive } \\
\text { network traffic }\end{array}$ \\
\hline Database Server & No special requirements. & $\begin{array}{c}\text { Server task is only to fetch and } \\
\text { update data, so it depends upon } \\
\text { size of data in the server. }\end{array}$ \\
\hline
\end{tabular}

\section{Objectives of the Study}

The objectives of the case study are given as follows:

1. To compare rule-based technology and conventional software development technology for implementation of healthcare edits.

2. To study how the rule-based technology and conventional software development technology have been used for knowledge representation, utilization and rationalization in Health Informatics domain.

3. To familiarize healthcare professionals with underlying software technologies being used in management of healthcare data. 


\subsection{Hypothesis}

The Null hypothesis is that, there is no difference of time in implementation of medical billing edits using rule based programming and using conventional programming. The hypothesis is constituted only for objective 3 since that is the only assessable and measureable objective listed in section 2.

The following hypothesis (equation 1 and 2) was developed for the study.

$$
\text { Ho (Null Hypothesis, } \mu R-\mu C=0 \text { or } \mu R=\mu C
$$

$$
\text { H1 (Alternate Hypothesis, } \mu R-\mu C \neq 0 \text { or } \mu R \neq \mu C
$$

Where $\mu \mathrm{R}$ denotes the average implementation time of system checks (healthcare edits) through rule-based programming and $\mu \mathrm{C}$ denotes the average implementation time of system checks (healthcare edits) through conventional programming. Implementation time depicts total time spent on each check from analysis to coding and making it operational. In the next section methodology of research has been described.

\section{Proposed Method}

In order to meet objective 2 and 3 of the study (as given in Section 2), we propose a method of medical claim processing that has been selected as application domain to test the above mentioned research hypothesis, mainly because it is a knowledge rich domain, where thousands of rules and regulations have been defined. Advantage in healthcare management domain is saving providers' precious time from data management related activities.

\subsection{Search Strategy and Study Selection}

This research proposed a mechanism for implementing rule-based healthcare edits. Rule-based healthcare edits are claimed to improve the performance of managing healthcare edits with respect to time and human error. Two teams (each comprising of two members) with approximately same skills in software development were assigned task of implementing the rules and regulations related to medical claim processing. Both the members of the team were having expertise skills in software development. The participants are working in a medical billing company in software development section. One team was using conventional software development technology technique and the other team was using rule-based technology to develop the software. Time taken by both the teams for encoding of rules and regulations of medical claim processing was recorded as major part of this research study.

\subsection{Data Sources}

Medical edit is not a technical term. It is devised for this paper to encapsulate the concept of changes in medical claims that are asked by the user of medical service. This term is used in medical claim billing. In this study, a sample of 100 medical billing edits was selected; which were implemented simultaneously by the two teams; one using conventional software development technology and other team using rule-based technology. The data depicted time (in hours: minutes) consumed to implement particular edit through rule-based technology and conventional software development technology consecutively. 


\subsection{Inclusion Criteria}

An edit is requested after submission of a medical claim. For an edit to be processed, it should qualify a predefined criterion. Prior to the implementation of rule-based technology, the conventional software development technology was being used for implementation of edits. During this research multiple phases of edit processing and inclusion were practically studied. The inclusion of edit depends upon the domain of edit, its alignment with the rules, time of request and amount of claim. In this study, critical evaluation of 100 edits processed by conventional systems and rule-based technology are considered.

\subsection{Exclusion Criteria}

Complexity of the edits is the major criteria for exclusion from implementation stage of this research study. Therefore, the edits like MEE (Mutually Exclusive Edits), NCCI (National Correct Codding Initiative) have not been included as it will require more complex programming for their implementation.

\subsection{Analysis of Data}

To analyze the above-mentioned hypothesis Statistical Package for Social Science (SPSS) with the latest version (V24.0) was applied. SPSS is the modern analytical approach and user-friendly software. It allows multiple kinds of analysis, the transformation of data and forms of output. The following statistical techniques were applied:

Paired t-Test: To compare two different programming techniques on the same checks Paired t-test was applied [18]. Paired T-Test is used to find the difference between two variables that are used on the same subject. The subject variables are projected on n different time intervals with all the other relative information as same. In this study, a total 100 system checks were selected and implementation time of each check by rule-based programming and conventional programming was compared.

Cronbach's Alpha: To measure the internal consistency of sample set as a group Cronbach's alpha [19] was used. Cronbach's alpha is a measure of scale reliability. To calculate the inter correlation among the two test items namely rule-based programming and conventional programming. The standardized formula of Cronbach's Alpha is given in equation 3:

$$
\alpha=\frac{N \cdot c^{-}}{\mathrm{v}^{-}+(\mathrm{N}-1) \cdot \mathrm{c}^{-}}
$$

Where $\mathrm{N}$ refers to the number of sample items; $\mathrm{c}^{-}$refers to the average covariance between sample items, and $\mathrm{v}^{-}$refers to the average variance of each sample item.

\section{Result}

Table 2 shows the time taken by the implementation teams in production rule-based programs and conventional if-then programs. The test is based on 100 edit implemented using both the teams respectively. In Table 2, the column 'As Rule' shows the implementation time of the edit in the form of Production-Rule, while the column 'As IF-Then' shows the implementation time as If-Then statement using conventional programming technology. 
Table 2. Time to execute rule-based and conventional if-then methods

\begin{tabular}{|c|c|c|c|}
\hline Sr & Case & $\begin{array}{l}\text { As Rule } \\
\text { (H:M) }\end{array}$ & $\begin{array}{l}\text { As } \\
\text { If-Then } \\
\text { (H:M) }\end{array}$ \\
\hline 1 & The claim is to be blocked if the medication is not payable. & $0: 40$ & $1: 00$ \\
\hline 2 & $\begin{array}{l}\text { No charges will be added to the amount of insurance if the admin } \\
\text { codes are processed only. }\end{array}$ & $1: 00$ & $1: 30$ \\
\hline 3 & $\begin{array}{l}\text { IF Medicare is given as insurance company and given code is } 82274 \\
\text { and G0328 THEN change the rule and add QW as modifier. }\end{array}$ & $1: 00$ & $1: 10$ \\
\hline 4 & $\begin{array}{l}\text { IF certain code lies in the range of 92980-92982, THEN the user } \\
\text { must pick one of the modifier from the list (LC, LD or RC). }\end{array}$ & $0: 30$ & 1:00 \\
\hline 5 & $\begin{array}{l}\text { IF procedure codes are } 81003 \text { and } 82570 \text { THEN add modifier QW } \\
\text { to the claim. }\end{array}$ & $0: 40$ & $1: 40$ \\
\hline 6 & $\begin{array}{l}\text { IF secondary insurance is Medicaid THEN do not bill to the patient, } \\
\text { rather adjust the remaining due amount. }\end{array}$ & $0: 30$ & $1: 40$ \\
\hline 7 & $\begin{array}{l}\text { IF place of service is office THEN the physician who attended and } \\
\text { the physician who billed should be the same. }\end{array}$ & $0: 40$ & $2: 10$ \\
\hline 8 & $\begin{array}{l}\text { IF the type of insurance is set to Medicaid THEN the bill should be } \\
\text { debited to Medicaid. }\end{array}$ & $0: 45$ & $1: 00$ \\
\hline 9 & $\begin{array}{l}\text { IF special codes for care and visits are used in the claim THEN add } \\
25 \text { to the final code. }\end{array}$ & $0: 30$ & 1:00 \\
\hline 10 & $\begin{array}{l}\text { IF the bill is referred to Medicaid with some priority package THEN } \\
\text { append modifier SE with vaccine codes. }\end{array}$ & $0: 30$ & $1: 00$ \\
\hline 11 & $\begin{array}{l}\text { IF practice code is } 150 \text { AND refer to Alliance Inc. located in Holly } \\
\text { springs THEN the case should be referred to Dr. Lyons, Michael. }\end{array}$ & 1:00 & $1: 25$ \\
\hline 12 & $\begin{array}{l}\text { IF practice code is } 150 \text { AND service asked in the office and asked } \\
\text { location is Hernando THEN the case should be referred to Dr. } \\
\text { Lyons, Michael. }\end{array}$ & $0: 45$ & $1: 20$ \\
\hline 13 & $\begin{array}{l}\text { IF practice code is } 151 \text { AND service asked in the office AND asked } \\
\text { location is Southaven THEN the case should be referred to Dr. } \\
\text { Wenzler, Robert. }\end{array}$ & $0: 40$ & $1: 25$ \\
\hline 14 & $\begin{array}{l}\text { IF procedure code is used from the list }(59025,76801,76805 \text {, } \\
76811,76815,76816,76817,76818,76819,76820,76830,76946) \\
\text { THEN apply modifier } 26 \text { with the procedure code. }\end{array}$ & $0: 35$ & $1: 10$ \\
\hline 15 & $\begin{array}{l}\text { IF practice code is } 152 \text { and procedure code is } 96118 \text { THEN inform } \\
\text { the account manager (Vivian) AND adjust the procedure code. }\end{array}$ & $0: 35$ & $1: 15$ \\
\hline 16 & $\begin{array}{l}\text { IF the ID of payer is } 5273884 \text { THEN the amount be adjusted with } \\
\text { the sources } Z \text { or X. }\end{array}$ & $0: 35$ & $1: 20$ \\
\hline 17 & $\begin{array}{l}\text { IF practice code is } 153 \text { AND practice location does not have } 9 \text { digit } \\
\text { zip code THEN update the zip code. }\end{array}$ & $0: 40$ & $1: 35$ \\
\hline
\end{tabular}




\begin{tabular}{|c|c|c|c|}
\hline 18 & $\begin{array}{l}\text { IF practice code is } 154 \text { AND practice location does not have } 9 \text { digit } \\
\text { zip code THEN update the zip code. }\end{array}$ & $0: 55$ & $1: 40$ \\
\hline 19 & $\begin{array}{l}\text { IF procedure code is } 97110 \text { THEN set amount billed to } \$ 50.00 \text { and } \\
\text { unit as } 1 .\end{array}$ & $0: 40$ & $1: 45$ \\
\hline 20 & $\begin{array}{l}\text { IF procedure code is } 97112 \text { THEN set } 2 \text { units in } 2 \text { lines and they will } \\
\text { be } \$ 50.00 \text { each. }\end{array}$ & $0: 45$ & $1: 50$ \\
\hline 21 & $\begin{array}{l}\text { IF procedure code is } 97530 \text { THEN set } 2 \text { units with charges } \$ 50.00 \\
\text { for each unit. }\end{array}$ & $0: 40$ & 1:05 \\
\hline 22 & $\begin{array}{l}\text { IF practice code is } 154 \text { AND procedure code is of physical therapy } \\
\text { THEN the physician selected for billing should be Melissa } \\
\text { Makower. }\end{array}$ & $0: 40$ & $1: 20$ \\
\hline 23 & $\begin{array}{l}\text { IF date of death }<\text { date of service THEN the claim should not be } \\
\text { processed. }\end{array}$ & $0: 20$ & $0: 50$ \\
\hline 24 & $\begin{array}{l}\text { IF code lies in the range 11982-11983 THEN V25.43 should be } \\
\text { there in the list of diagnostic codes. }\end{array}$ & $0: 40$ & $2: 10$ \\
\hline 25 & $\begin{array}{l}\text { IF code is not in line with the gender THEN the claim should not be } \\
\text { accepted. }\end{array}$ & $0: 30$ & $2: 30$ \\
\hline 26 & $\begin{array}{l}\text { IF code is not in line with the age THEN the claim should not be } \\
\text { accepted. }\end{array}$ & $0: 50$ & $3: 30$ \\
\hline 27 & $\begin{array}{l}\text { IF both the diagnosis codes } 25.40 \text { and } 61.5 \text { are referred in a claim } \\
\text { THEN specify the mark-center as clear. }\end{array}$ & $0: 40$ & $1: 40$ \\
\hline 28 & $\begin{array}{l}\text { IF ambulance related procedure code used THEN the codes for } \\
\text { distance of transportation, its reason code and code for ambulance } \\
\text { be picked. }\end{array}$ & $0: 15$ & $4: 10$ \\
\hline 29 & $\begin{array}{l}\text { IF procedure code from }(90680,90670,90707,90716,90700 \text {, } \\
\text { 90713) THEN national drug code must exist. }\end{array}$ & $0: 50$ & $1: 40$ \\
\hline 30 & $\begin{array}{l}\text { IF state is New York THEN procedure code for transfusions } \\
\text { (36430) is allowed to be billed only once a day. }\end{array}$ & 1:00 & $3: 00$ \\
\hline 31 & $\begin{array}{l}\text { IF } 155 \text { is entered as given code THEN give } 15 \% \text { discount in the } \\
\text { payables. }\end{array}$ & $1: 30$ & $1: 25$ \\
\hline 32 & $\begin{array}{l}\text { IF practice code is } 156 \text { AND procedure code is } 90471 \text { THEN use } \\
\text { administration code G0008 instead of } 90471 .\end{array}$ & $0: 38$ & 2:02 \\
\hline 33 & $\begin{array}{l}\text { IF ID= } 5001525 \text { AND codes lie in the list }(95903,95904,95934 \text {, } \\
\text { 95861) THEN the notes written by the physician be appended. }\end{array}$ & $0: 55$ & $2: 20$ \\
\hline 34 & $\begin{array}{l}\text { IF the given ID of the bill payer is } 5002046 \text { THEN policy number } \\
\text { should contain first ten numerals. }\end{array}$ & $0: 30$ & $0: 55$ \\
\hline 35 & $\begin{array}{l}\text { IF procedure code is from L1960, L1970, L1990, L2020 and L2405 } \\
\text { THEN patient's age limit is from } 21 \text { to } 65 \text { years. }\end{array}$ & $0: 40$ & 1:05 \\
\hline
\end{tabular}




\begin{tabular}{|c|c|c|c|}
\hline 36 & $\begin{array}{l}\text { IF date of service is on or after August 1, 2010, THEN modifier ZS } \\
\text { will no longer be reimbursable with MRI, MRA and PET scans. }\end{array}$ & 1:30 & $2: 40$ \\
\hline 37 & $\begin{array}{l}\text { IF procedure code is T1001 or S9470 THEN evaluation and } \\
\text { management codes not be added on the same time. }\end{array}$ & $0: 50$ & $1: 55$ \\
\hline 38 & IF procedure code is 83655 THEN patient age limit is 0 to 2 years. & $0: 45$ & $2: 00$ \\
\hline 39 & $\begin{array}{l}\text { IF date of service of claim is equal or prior to } 90 \text { days from the } \\
\text { current date THEN mention late filing reason. }\end{array}$ & $0: 50$ & 1:05 \\
\hline 40 & $\begin{array}{l}\text { IF code is } 36415 \text { and } 85025 \text { billed together THEN the claims under } \\
\text { code } 36415 \text { are not reimbursed. }\end{array}$ & $0: 40$ & $2: 10$ \\
\hline 41 & $\begin{array}{l}\text { IF ID }=5003748 \text { and responsibility is not accepted THEN bill will } \\
\text { not be sent to the patient. }\end{array}$ & $1: 20$ & $2: 00$ \\
\hline 42 & $\begin{array}{l}\text { IF ID }=5004229 \text {, THEN the statement should be prefixed with } G \\
\text { and should have } 10 \text { numerals. }\end{array}$ & $0: 39$ & $1: 31$ \\
\hline 43 & $\begin{array}{l}\text { IF ID }=5004485 \text { THEN the character length of policy number must } \\
\text { be } 8,9 \text { or } 11 \text {. }\end{array}$ & $1: 00$ & $2: 30$ \\
\hline 44 & $\begin{array}{l}\text { IF Champva Health is the insurance company THEN 'self' should } \\
\text { be entered in admin rel. }\end{array}$ & $0: 30$ & $1: 50$ \\
\hline 45 & $\begin{array}{l}\text { IF ID= 500763, THEN the submission should not be made with } \\
\text { group number given by the insurance company. }\end{array}$ & $0: 30$ & $1: 00$ \\
\hline 46 & $\begin{array}{l}\text { IF group no = policy no THEN do not process the claim and rectify } \\
\text { the same. }\end{array}$ & $0: 30$ & $1: 20$ \\
\hline 47 & $\begin{array}{l}\text { IF code lies within the range } 22520 \text { - } 22525 \text { THEN the code for } \\
\text { diagnostics should be picked from the list (198.5, 203.0, 203.1, } \\
\text { 228.09, 238.6, 228.0, 733.13). Any other service requested should } \\
\text { not be accepted. }\end{array}$ & $0: 50$ & $2: 10$ \\
\hline 48 & $\begin{array}{l}\text { IF health first health plan used THEN a change should be made in } \\
\text { the prior authentication against the service code. }\end{array}$ & $0: 40$ & $1: 50$ \\
\hline 49 & $\begin{array}{l}\text { IF the ID of the payer is } 500950 \text {, THEN the policy number should } \\
\text { not contain more than } 11 \text { numerals. }\end{array}$ & $0: 40$ & $1: 30$ \\
\hline 50 & $\begin{array}{l}\text { IF code lie in the range of } 58150-57270 \text { THEN the primary code } \\
\text { must be fixed at } 58150 \text { and backup code at CPT } 57270 \text {. }\end{array}$ & $0: 30$ & $1: 20$ \\
\hline 51 & IF the given code is 80055 THEN the gender must be female. & $0: 45$ & 1:30 \\
\hline 52 & $\begin{array}{l}\text { IF procedure code } 90471 \text { is used THEN do not use procedure code } \\
90473 .\end{array}$ & $0: 40$ & $1: 50$ \\
\hline 53 & $\begin{array}{l}\text { IF the given code for vaccination is } 90632 \text { is used AND given } \\
\text { location is California THEN apply diagnostic codes flagging critical } \\
\text { at risk. }\end{array}$ & $1: 10$ & 3:11 \\
\hline
\end{tabular}




\begin{tabular}{|c|c|c|c|}
\hline 54 & $\begin{array}{l}\text { IF the given claim is sent to Medicare AND code }=90658 \text { THEN use } \\
\text { insert the code G0008. }\end{array}$ & $0: 53$ & $2: 31$ \\
\hline 55 & $\begin{array}{l}\text { IF the given code for vaccination is } 90707 \text { is used THEN diagnosis } \\
\text { code should be V06.4. }\end{array}$ & $0: 40$ & $1: 55$ \\
\hline 56 & $\begin{array}{l}\text { IF code allocated to vaccination is } 90733 \text { THEN the diagnostic code } \\
\text { representing high risk be allocated V03.89. }\end{array}$ & $0: 49$ & $2: 02$ \\
\hline 57 & $\begin{array}{l}\text { IF state is Hawaii or New jersey or Texas AND procedure code is } \\
90746 \text { THEN use high risk diagnosis code V05.3. }\end{array}$ & $0: 59$ & 1:59 \\
\hline 58 & $\begin{array}{l}\text { IF procedure code is in range 90951- } 90953 \text { THEN patient should } \\
\text { be younger than } 2 \text { years. }\end{array}$ & $0: 30$ & $1: 45$ \\
\hline 59 & $\begin{array}{l}\text { IF procedure code is from range } 97110-97542 \text { THEN procedure } \\
\text { code } 97150 \text { should not be used on same date of service. }\end{array}$ & $1: 20$ & $2: 50$ \\
\hline 60 & $\begin{array}{l}\text { IF discharge code (99238-99239) is being used THEN 'from' and } \\
\text { 'to' dates should be same. }\end{array}$ & $0: 40$ & $2: 05$ \\
\hline 61 & $\begin{array}{l}\text { IF the given code lies in the range } 00100 \text { - } 01999 \text { THEN the time for } \\
\text { start of end of anesthesia should be given. }\end{array}$ & 1:05 & $2: 25$ \\
\hline 62 & $\begin{array}{l}\text { IF modifier G8 is being used in a claim THEN procedure code } \\
\text { should be from }(00100,00300,00400,00160,00532,00920) \text {. }\end{array}$ & $0: 45$ & $1: 50$ \\
\hline 63 & $\begin{array}{l}\text { IF anesthesia code is being used in a claim THEN modifiers LT and } \\
\text { RT cannot be used. }\end{array}$ & $0: 40$ & $1: 45$ \\
\hline 64 & $\begin{array}{l}\text { IF procedure code is G0389 THEN use V81.2 as primary diagnosis } \\
\text { code. }\end{array}$ & $0: 50$ & $2: 10$ \\
\hline 65 & $\begin{array}{l}\text { IF insurance is Medicare THEN do not use consultation codes in a } \\
\text { claim. }\end{array}$ & $1: 00$ & $3: 50$ \\
\hline 66 & $\begin{array}{l}\text { IF Clinical Laboratory Improvement Amendments number is not } \\
\text { valid THEN CLIA info should be renewed. }\end{array}$ & 1:05 & $2: 20$ \\
\hline 67 & $\begin{array}{l}\text { IF date of service is lesser than the date of execution THEN } \\
\text { reproduce the claim. }\end{array}$ & $0: 50$ & $1: 50$ \\
\hline 68 & $\begin{array}{l}\text { IF service units are not equal to the number of vaccines THEN } \\
\text { rectify the claim. }\end{array}$ & $0: 45$ & $3: 15$ \\
\hline 69 & $\begin{array}{l}\text { IF the code lies in range E812.0-E812.9 THEN it is necessary to } \\
\text { give date of accident and position. }\end{array}$ & 0.42 & $1: 58$ \\
\hline 70 & $\begin{array}{l}\text { IF claim is electronically prescribed THEN do not use G-Code in } \\
\text { the claim. }\end{array}$ & $0: 50$ & $3: 30$ \\
\hline 71 & $\begin{array}{l}\text { IF procedure code is G0247 THEN include either G0245 or G0246 } \\
\text { on the same date of service. }\end{array}$ & $1: 29$ & $4: 07$ \\
\hline 72 & $\begin{array}{l}\text { IF the claim includes CPT G8553 and G8443 and their charges in } \\
\text { the claim are NIL THEN in the procedure code EDI should remain }\end{array}$ & $1: 25$ & $4: 59$ \\
\hline
\end{tabular}




\begin{tabular}{|c|c|c|c|}
\hline & marked only for Medicare insurance. & & \\
\hline 73 & $\begin{array}{l}\text { IF the address of the claimant and the guarantor is same THEN send } \\
\text { the claim for necessary modification. }\end{array}$ & $0: 40$ & $2: 25$ \\
\hline 74 & $\begin{array}{l}\text { IF age }<18 \text { years and there is no financial supporter THEN the } \\
\text { option of guarantor info should be marked. }\end{array}$ & $0: 50$ & $2: 10$ \\
\hline 75 & $\begin{array}{l}\text { IF the ID allocated to the payer is equal to 5003832, THEN the first } \\
\text { alphabet of policy number should be F. }\end{array}$ & $0: 50$ & $2: 25$ \\
\hline 76 & $\begin{array}{l}\text { IF procedure code is J3420 THEN it should be mapped with any of } \\
\text { these diagnosis codes }(266.2,281.0,579.8)\end{array}$ & $1: 35$ & $2: 20$ \\
\hline 77 & $\begin{array}{l}\text { IF the physician to be billed is different from the physician who } \\
\text { took up the case THEN the Specifier should be changed from SA to } \\
52 .\end{array}$ & $1: 50$ & $5: 40$ \\
\hline 78 & $\begin{array}{l}\text { IF units are more than } 400 \text { THEN attach medical notes for the } \\
\text { procedure }\end{array}$ & $0: 50$ & $2: 25$ \\
\hline 79 & $\begin{array}{l}\text { IF the codes used for billing are taken from the hospital THEN the } \\
\text { service should be equated with IH. }\end{array}$ & $0: 55$ & $2: 40$ \\
\hline 80 & $\begin{array}{l}\text { IF diagnosis code is within range } 800 \text { to } 999 \text { THEN accident date is } \\
\text { required by payers. }\end{array}$ & $1: 00$ & $4: 30$ \\
\hline 81 & $\begin{array}{l}\text { IF code }=82270 \text { THEN the code will be aligned with } \mathrm{Z} \text { source. No } \\
\text { other adjustment will be made. }\end{array}$ & $1: 50$ & $6: 00$ \\
\hline 82 & $\begin{array}{l}\text { IF code }=90656 \text { or } 90658 \text { THEN the diagnostic code to be used will } \\
\text { be V04.81 and pointer will accordingly be adjusted. }\end{array}$ & $1: 10$ & $2: 30$ \\
\hline 83 & $\begin{array}{l}\text { IF patient's age }<18 \text { THEN V20.2. code is deployed AND IF } \\
\text { patient's age }>=18 \text {, THEN V70.0 }\end{array}$ & $1: 30$ & $4: 00$ \\
\hline 84 & $\begin{array}{l}\text { IF the payment entry at the end is rejected under code } 03 \text { and } \\
\text { due_amount }>0 \text { THEN status_of_patient= 'new'. }\end{array}$ & $1: 10$ & $5: 10$ \\
\hline 85 & $\begin{array}{l}\text { IF code }=160 \text { AND weekday of service is in the list (Tuesday, } \\
\text { Wednesday, Thursday, Friday) AND service is offered in office and } \\
\text { located in Turnersville THEN physician to be billed is Dr. John }\end{array}$ & $1: 10$ & $6: 50$ \\
\hline 86 & $\begin{array}{l}\text { IF code }=160 \text { AND weekday of service is Monday AND located in } \\
\text { Turnersville AND service is offered in office THEN physician to be } \\
\text { billed is Dr. Doe }\end{array}$ & $1: 20$ & $4: 30$ \\
\hline 87 & $\begin{array}{l}\text { IF there exist more than one surgery codes THEN add } 51 \text { as } \\
\text { modifier. }\end{array}$ & $1: 05$ & $2: 50$ \\
\hline 88 & $\begin{array}{l}\text { IF code }=99354 \text {, AND no facility there THEN service_place }= \\
\text { outpatient hospital. }\end{array}$ & $1: 30$ & $5: 20$ \\
\hline
\end{tabular}




\begin{tabular}{|c|c|c|c|}
\hline 89 & $\begin{array}{l}\text { IF a visit because of previous payment is rejected, THEN claim be } \\
\text { resubmitted with the code IN (99211 - } 99215 \text { / } 99391 \text { - 99397). }\end{array}$ & $1: 15$ & $4: 55$ \\
\hline 90 & $\begin{array}{l}\text { IF balance under } \$ 1 \text { THEN amend the amount of patient as per } \\
\text { given inst manual. }\end{array}$ & $0: 40$ & $2: 30$ \\
\hline 91 & $\begin{array}{l}\text { IF self-pay patient pays } \$ 50.00 \text { THEN according to special } \\
\text { instructions the bill will not be reissued after payment. }\end{array}$ & $1: 15$ & 3:05 \\
\hline 92 & $\begin{array}{l}\text { IF consult code is between (99241 - 99245) THEN according to } \\
\text { special instructions, replace it with office visit (99201 - 99205). }\end{array}$ & $0: 55$ & $2: 10$ \\
\hline 93 & $\begin{array}{l}\text { IF Medicare denied procedure } 77080 \text { that shows that the care was } \\
\text { not essential THEN the code be resubmitted to the company of code } \\
\text { V49.81 (Female) and } 733.00 \text { (Male). }\end{array}$ & $1: 23$ & $5: 59$ \\
\hline 94 & $\begin{array}{l}\text { IF primary diagnosis code is } 222.8 \text { THEN add secondary code } \\
\text { V25.2 }\end{array}$ & $0: 40$ & $1: 40$ \\
\hline 95 & $\begin{array}{l}\text { IF hospital= Barrett Hospital AND Medicare OR Medicaid-MT } \\
\text { THEN change the code to } 26 \text { and remove TC. }\end{array}$ & $1: 20$ & $6: 20$ \\
\hline 96 & $\begin{array}{l}\text { IF the admin codes in the list }(90471,90472,90460,90461) \text { are not } \\
\text { accepted by the insurance company and the code is } 02 / 12 / 18 \text {, } \\
\text { THEN the code should not be submitted. The amount may be } \\
\text { adjusted with source } Z \text {. }\end{array}$ & $1: 10$ & $6: 30$ \\
\hline 97 & $\begin{array}{l}\text { IF the disease is flu AND vaccines IN (90656, FC448, 90660, } \\
\text { 90658, G8482, 90661, 4274F, 90655, G8483, 90657, 90662, } \\
\text { 90663, , FS448, G8424, G8425, G8484) THEN change and add } \\
\text { modifier 2. }\end{array}$ & $0: 50$ & $2: 50$ \\
\hline 98 & $\begin{array}{l}\text { IF insurance is Medicaid THEN according to the code of } \\
\text { administration may not be submitted as per special instructions. }\end{array}$ & $1: 25$ & $5: 40$ \\
\hline 99 & $\begin{array}{l}\text { IF service offered does not have the capacity to offer services } \\
\text { THEN the payment of CPT } 87430 \text { be adjusted with Z. }\end{array}$ & $1: 05$ & $6: 20$ \\
\hline \multirow[t]{2}{*}{100} & $\begin{array}{l}\text { IF practice code is } 171 \text { AND weekday = Tuesday or Thursday AND } \\
\text { the service is given in office THEN the claim can't be located in } \\
\text { Toms River. }\end{array}$ & $0: 50$ & $4: 10$ \\
\hline & Grand total & 92:04 & $\begin{array}{l}249: 3 \\
2\end{array}$ \\
\hline
\end{tabular}




\section{Analysis and Discussion}

First part of this section presents empirical analysis of results, while in order to scientifically confirm the authenticity of results, statistical analysis has been given in the later part of this section. In Table 2, column 'Sr' is the order according to which the production rules were applied to validate the checks. The checks are dependent on each other and those applied in lateral stage are effected by the ones applied earlier. These cross-dependencies of production rules caused increase in implementation time. The complexity of debugging also increased with increased depth of inheritance tree and number of functions. On the other rule, the complexity of production rules remains constant and will not be affected by increasing these cross-dependencies to any extent.

The results empirically have shown that the time spent on programming and implementing the billing edits is almost thrice to the same implemented through production rules (91 Hours vs. 254.5 Hours). This means, that the use of rule based systems increases the performance of a healthcare professional who can now design and test billing edits three times faster than the conventional application programs written by the programmers.

Moreover, it is observed that the edits implemented earlier in sequence are affecting the edits implemented later. As discussed earlier, in addition to this, the time taken in implementing such modules with higher depth of inheritance tree and cyclomatic complexity, the coding becomes increasingly difficult so as the debugging. Production rule development, on the other hand absorbs the effect of increase in the size of edits and won't show any remarkable increase in time taken to complete the execution. Fig. 1, given below depicts the implementation curves of both techniques graphically.

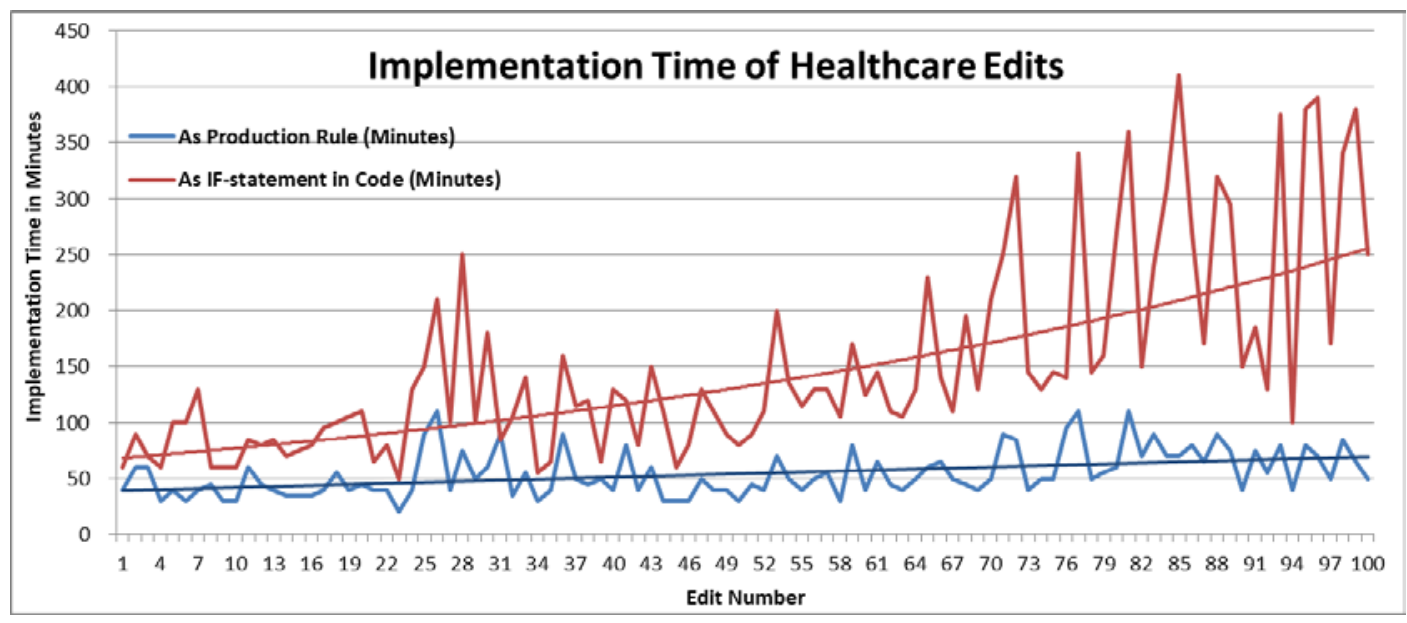

Fig. 1. Comparison of implementation time of healthcare edits

Rule-based technology has the linear implementation curve while the conventional technology is not linear in increase. This implies that with the increase in number of edits conventional technology may fail very soon. By making this comparison objective 1 of the study is also achieved.

In order to perform statistical analysis SPSS Variable sheet was developed showing two variables namely time (in minutes) to implement edit by rule-based technology and time (in minutes) to encode/implement the same edit by conventional software development technology. Then the data of paired variables was imported to SPSS data sheet. Data was 
analyzed using two-tailed t-tests, Cronbach's alpha. The results and interpretation of the data analysis are as follows:

\subsection{Paired t-Test}

Two-tailed t-test at 95\% level of significance was conducted to compare means of a sample of 100 checks. The sample of 100 was taken so that it could represent the whole population in an accurate manner.

The results in Table 3 depict that to implement a rule involving all step analysis, the definition of the rule, testing of the rule and moving the rule to production, on average 54.60 or approximately 55 minutes are required; whereas to update/write code, 152.75 or approximately 152.75 minutes are required.

Table 3. Development time stats of paired inputs

\begin{tabular}{|c|c|c|c|c|}
\hline Characteristics & Average & N & SD & Error Mean \\
\hline \hline Dev. Time as Rule & 54.60 & 100 & 20.384 & 2.038 \\
\hline Dev. Time as Rule & 152.75 & 100 & 89.667 & 8.967 \\
\hline
\end{tabular}

Hence implementation of checks by conventional programming takes 3 times more time than the implementation of healthcare edits by rule-based technology.

$\mathrm{H}_{\mathrm{o}}$ (Null Hypothesis, $\mu \mathrm{R}-\mu \mathrm{C}=0$

Or $\mu \mathrm{R}=\mu \mathrm{C}$

Where $\mu \mathrm{R}$ represents average time or arithmetic mean to develop system check by rule-based programming and $\mu \mathrm{C}$ represents average time to implement system check by conventional programming. The Table 4 shows that the null hypothesis (stating that the equal average time is required to apply system checks by rule-based programming and conventional programming) is rejected at $95 \%$ level of significance.

Table 4. Paired Samples Test

\begin{tabular}{|c|c|c|c|c|c|c|c|c|}
\hline & \multicolumn{5}{|c|}{ Paired Differences } & \multirow[b]{3}{*}{$\mathbf{t}$} & \multirow[b]{3}{*}{ df } & \multirow{3}{*}{$\begin{array}{c}\text { Sig. } \\
\text { (2-tail } \\
\text { ed) } \\
\end{array}$} \\
\hline & \multirow[b]{2}{*}{ Mean } & \multirow{2}{*}{\begin{tabular}{c|} 
Std. \\
Deviation \\
\end{tabular}} & \multirow{2}{*}{$\begin{array}{c}\text { Std. } \\
\text { Error } \\
\text { Mean } \\
\end{array}$} & \multicolumn{2}{|c|}{$\begin{array}{c}\text { 95\% Confidence Interval } \\
\text { of the Difference }\end{array}$} & & & \\
\hline & & & & Lower & Upper & & & \\
\hline $\begin{array}{l}\text { Time taken to } \\
\text { extract rule - } \\
\text { time taken to } \\
\text { code the } \\
\text { program }\end{array}$ & -98.150 & 76.919 & 7.692 & -113.412 & -82.888 & -12.76 & 99 & 0.000 \\
\hline
\end{tabular}

\subsection{Reliability}

To measure the internal consistency or reliability of the sample items, Cronbach's alpha was administered, depicted by Table 5. The reliability ranges from 0 to 1 . 
Table 5. Case Processing Summary

\begin{tabular}{|c|c|c|}
\hline Cases & $\mathbf{N}$ & $\mathbf{\%}$ \\
\hline \hline Valid & 100 & 100.0 \\
\hline Excluded & 0 & 0.0 \\
\hline Total & 100 & 100.0 \\
\hline
\end{tabular}

The value of Cronbach's Alpha for 2 items is 0.462 which is a low level of internal consistency for this sample. As $\alpha \leq 0.5$ depicts that sample items are independent of one another so $\alpha=0.462$ shows that time to implement system check by rule-based programming is independent of time to implement system check by conventional programming. High covariance between each pair leads to high variation among the total time consumed to execute system checks by rule-based programming and conventional programming.

The statistics specifies that rule-based programming is three times more time efficient than conventional programming. The data analysis showed that the hypothesis stating that on average equivalent time was used to implement system check by conventional programming and rule-based programming was rejected at 95\% level of significance. Moreover, as Cronbach's alpha value is less than 0.5 so both the samples are independent or in other words time taken by conventional programming is independent of time take by rule-based programming. High covariance in each pair of the paired sample led to the high total variation between both samples.

\section{Conclusion}

Two technologies have been scientifically compared for the implementation of healthcare edits. Empirical analysis - authenticated statistically - has proved that rule-based technology is approximately 3 times more efficient than conventional software development technology. The results of the study are valuable when comparing either, pre and post implementation of rule-based technology or comparing two systems utilizing rule-based technology and conventional software development technology. The reason for which rule based systems outperformed others is their flexibility in approach and simplicity in managing the production rules. The rules are extracted from the existing datasets and to add, remove or modify a rule is not a design time issue. Rules can be edited at runtime by editing the relevant data only without making any change to the source code. Similarly, rule based programming is suitable when a large number of edits based on knowledge are expected within a dataset.

\section{Acknowledgement}

Many thanks to Healthcare IT Company 'MaxRemind' (http://www.mremind.com) for providing excellent research environment. 


\section{References}

[1] Tegegne, E. Workineh, P. Seppänen, and M. O. Ahmad, "Software development methodologies and practices in start-ups,” IET Software, vol. 13, no. 6, pp. 497-509, 2019. Article (CrossRef Link)

[2] F. S. Ujager and A. Mahmood, “A context-aware accurate wellness determination (caawd) model for elderly people using lazy associative classification,” Sensors, vol. 19, p. 1613, 2019. Article (CrossRef Link)

[3] S. Hussain, M. Hussain, M. Afzal, J. Hussain, J. Bang, H. Seung, and S. Lee, "Semantic preservation of standardized healthcare documents in big data," International journal of medical informatics, vol. 129, pp. 133-145, 2019. Article (CrossRef Link)

[4] C. Dainton and C. H. Chu, "A review of electronic medical record keeping on mobile medical service trips in austere settings,” International journal of medical informatics, vol. 98, pp. 33-40, 2017. Article (CrossRef Link)

[5] K. A. Kelley, H. E. Hoops, L. Palmer, N. A. Cohen, and K. J. Brasel, "Implementation of a medical coding curriculum for surgery residents,” The American Journal of Surgery, vol. 217, pp. 834-838, 2019. Article (CrossRef Link)

[6] M.-L. Sher, P. C. Talley, T.-J. Cheng, and K.-M. Kuo, "How can hospitals better protect the privacy of electronic medical records? Perspectives from staff members of health information management departments,” Health Information Management Journal, vol. 46, pp. 87-95, 2017. Article (CrossRef Link)

[7] D. Brahams, "A Claim Delayed May Be a Claim Denied," Medico-Legal Journal, vol. 75, no. 2, pp. 37-39, 2007. Article (CrossRef Link)

[8] V. Mantzana, M. Themistocleous, Z. Irani, and V. Morabito, "Identifying healthcare actors involved in the adoption of information systems,” European Journal of Information Systems, vol. 16, pp. 91-102, 2007. Article (CrossRef Link)

[9] T. Mäenpää, T. Suominen, P. Asikainen, M. Maass, and I. Rostila, "The outcomes of regional healthcare information systems in health care: a review of the research literature,” International journal of medical informatics, vol. 78, pp. 757-771, 2009. Article (CrossRef Link)

[10] P. M. Ginter, W. J. Duncan, and L. E. Swayne, The strategic management of health care organizations, John Wiley \& Sons, 2018. Article (CrossRef Link)

[11] O. Hanseth and K. Lyytinen, "Design theory for dynamic complexity in information infrastructures: the case of building internet," Enacting research methods in information systems, Springer, pp. 104-142, 2016. Article (CrossRef Link)

[12] I. Bowns, G. Rotherham, and S. Paisley, "Factors associated with success in the implementation of information management and technology in the NHS," Health Informatics Journal, vol. 5, pp. 136-145, 1999. Article (CrossRef Link)

[13] Y.K. Alotaibi, SBFM. ABFM, and F. Federico, "The impact of health information technology on patient safety,” Saudi Med Journal, vol. 38, pp. 1173-1180, 2017. Article (CrossRef Link)

[14] U. Abdullah, Data mining driven learning apprentice system for medical billing compliance, Foundation University, Islamabad, FUIEMS. Islamabad, Pakistan: Higher, 2012. Article (CrossRef Link)

[15] A. K. Akanbi, M. Masinde, “Towards the Development of a Rule-Based Drought Early Warning Expert Systems Using Indigenous Knowledge,” in Proc. of 2018 International Conference on Advances in Big Data, Computing and Data Communication Systems, pp. 1-8, 2018. Article (CrossRef Link)

[16] S. Chaudhari, V. Sardar, D.S. Rahul, M. Chandan, M.S.Shivakale, and K.R.Harini, "Performance Analysis of CNN AlexNet and VGGNet Models for Drought Prediction using Satellite Images," in Proc. of Innovation in Technology (ASIANCON) 2021 Asian Conference, pp. 1-6, 2021. Article (CrossRef Link)

[17] U. Abdullah, A. Ligęza, and K. Zafar, "Performance evaluation of rule-based expert systems: An example from medical billing domain,” Expert Systems, vol. 34, p. e12218, 2017. Article (CrossRef Link) 
[18] N. Kock, “One-tailed or two-tailed P values in PLS-SEM?,” International Journal of e-Collaboration (IJeC), vol. 11, pp. 1-7, 2015. Article (CrossRef Link)

[19] L. J. Cronbach, “Coefficient alpha and the internal structure of tests,” psychometrika, vol. 16, pp. 297-334, 1951. Article (CrossRef Link)

[20] M. Shaheen, U. Abdullah, "CARM: Context Based Association Rule Mining for Conventional Data,” Computers, Materials \& Continua, vol. 68, 2021. Article (CrossRef Link)

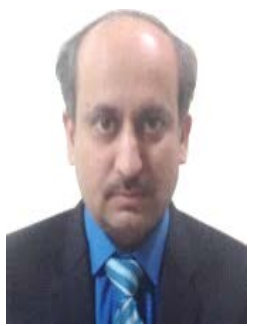

Dr. Umair Abdullah is currently working as Chief Technology Officer at MaxRemind Research \& Development Department, MaxRemind Inc. He has more than 20 years of teaching experience for the subjects of computer programming, data structures, data mining, artificial intelligence, operations research. Moreover, he has 7+ years of experience of working in healthcare IT industry where he lead the development of a rule based expert system for medical billing and coding domain. His research interests include software programming, data mining, knowledge based systems, expert systems.

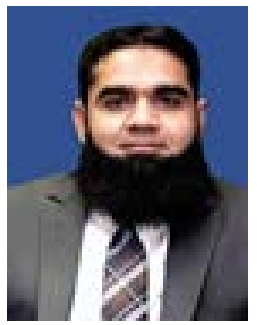

Prof. Dr. Muhammad Shaheen is a Professor/ Dean (Faculty of Engineering \& IT) at Faculty of Engineering and Information Technology, Foundation University Islamabad, Pakistan. He did his doctorate in computer science in 2011 and worked in the field of wisdom mining, data mining, artificial intelligence and remote sensing. He worked in diverse industrial and academic settings in his professional career of above seventeen years. He has number of research publications in the journals and conferences of international repute. His current research interests include wisdom mining, data mining, health big data, computer education and artificial intelligence. He is a senior member of IEEE and professional member of ACM, IAENG and SCI.

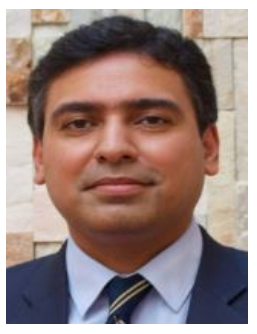

Dr. Farhan Sabir Ujager is the Senior Lecturer in the Faculty of Engineering \& Computing at De Montfort University Dubai. Dr. Ujager has more than 14 years of experience in teaching, research, and management, at different universities in Pakistan and United Arab Emirates.

His research interests include Smart and Sustainable Ambiance, Smart Healthcare, Cyber Security, Machine Learning and Data Mining, Wireless Sensor Networks and Optical Communication. He is currently researching in the Context-Aware Smart ambiance and healthcare applications. He has published in several reputed international journals and conference proceedings. 